\title{
Electrochemical Performance of Pulse Electrodeposited Sn-Ni/MWCNT Composite Anode for Lithium-Ion Batteries
}

\author{
M. Uysal*, H. GÖrmüş, R. KarslioĞlu, A. Alp and H. Akbulut \\ Sakarya University Engineering Faculty, Department of Metallurgical and Materials Engineering \\ Esentepe Campus, 54187, Sakarya, Turkey
}

\begin{abstract}
Grain size, and MWCNT content in the electrolyte of nanocrystalline Sn-Ni/MWCNT composite deposits produced from a solution containing nickel chloride and tin chloride at constant electrodeposition conditions (pulse on-time $T_{\text {on }}$ at $2.5 \mathrm{~ms}$ and pulse off-time $T_{\text {off }}$ at $7.5 \mathrm{~ms}$ ) but with different peak current densities were investigated. The structure of the electroplated thin film Sn-Ni/MWCNTs composite electrode is investigated by X-ray diffraction, scanning electron microscopy. Galvanostatic charge/discharge measurements were performed in the assembled CR2016 cells designed by using anode composite material produced by pulse electro co-deposition. These cells discharge capacities were cyclically tested by a battery tester at a constant current in voltage range between 0.02 and $1.5 \mathrm{~V}$. The electrochemical results showed that the increase in the discharge capacity of the assembled cell was produced when compared with conventionally used graphite lithium-ion batteries.
\end{abstract}

DOI: 10.12693/APhysPolA.125.353

PACS: 81.15.Pq, 82.47.Aa, 81.05.Mh

\section{Introduction}

Many studies have been focusing on replacing commercially used graphite anodes with other materials, with the aim of improving the capacity and energy density of lithium ion batteries. Among the candidate materials, Sn-based materials are particularly attractive as Sn has a high theoretical capacity of $994 \mathrm{mAh} \mathrm{g}^{-1}$, which is much higher than that of graphite $\left(372 \mathrm{mAh} \mathrm{g}^{-1}\right)$. However, the central problem for the practical application of a tin anode is the large volume change (about 300\%) during $\mathrm{Li}^{+}$insertion/extraction, which results in fast pulverization of electrode and thus large irreversible capacity loss leading to poor cycling performance $[1,2]$.

In order to improve the performance of pure Sn electrodes, extensive attention has been paid on tin-based intermetallic compounds, such as $\mathrm{Sn}-\mathrm{Cu}, \mathrm{Sn}-\mathrm{Co}, \mathrm{Sn}-\mathrm{Ni}$, etc. These alloy materials can provide a longer cycleability than that of pure tin [2]. Ni atoms form a matrix around the Sn atoms; this structure can restrict the volume change of Sn during its electrochemical reaction with $\mathrm{Li}$ because the $\mathrm{Ni}$ matrix plays only a buffer role, i.e., it does not react with $\mathrm{Li}$. However, since the volume change of $\mathrm{Sn}$ is not restricted completely, cracks are formed on the electrode surface during charging and discharging [3].

Recently, the nanocomposites of Sn-based alloy/carbonaceous materials were introduced to overcome this problem because of synergistic effect between carbonaceous materials and Sn [4]. Sn-Ni alloy can be prepared by different technique such as electrodeposition [5], sintering [6], ball milling [7]. In comparison, the electrodeposition presents significant advantages, particular

*corresponding author; e-mail: mehmetu@sakarya.edu.tr for the preparation materials of Li-ion battery. Electrodeposited anodes do not need conductive agents and binders, the microstructure of the deposits can also be significantly changed by well controlling the electrodeposition conditions, i.e., the chemical composition of the coating bath, the stirring conditions and the pulse current density [2].

Up to now, we did not find any report on about the synthesis and lithium storage performance of nanostructured $\mathrm{Sn}-\mathrm{Ni}$ alloy/multiwall carbon nanotube (MWCNT) composites prepared by pulse electrodeposition.

In this paper, $\mathrm{Sn}-\mathrm{Ni} / \mathrm{MWCNT}$ composite was prepared for the first time by pulse electrodeposition on copper that is served as a current collector. The charge-discharge tests demonstrated that the electrode of nanocomposites of $\mathrm{Sn}-\mathrm{Ni} / \mathrm{MWCNTs}$ exhibited a relatively high capacity and excellent cycleability when it was used as an anode of a lithium battery.

\section{Experimental}

\subsection{MWCNT functionalization}

To obtain good deposition, MWCNTs should be dispersed uniformly in the plating solution, and suspension must be stable. This is because the MWCNTs were easily coalesced in aqueous solution due to their high surface energy. In this investigation, surface treatment of MWCNTs was carried out using a solution nitric acid/ sulphuric acid to improve the dispersion of the CNTs into the electrodeposited Sn-MWCNT coating. The acid treatment not only removes most of the metal but also produces carboxyl, aldehyde, and other oxygen containing functional groups [8] on the surface of the MWCNTs and helps in the uniform dispersion of CNTs without any additional dispersing additive. The mixture was subsequently magnetically stirred at $100^{\circ} \mathrm{C}$ for $1 \mathrm{~h}$. Then they 
were further collected on $0.2 \mu \mathrm{m}$ filter, rinsed with distilled water, and dried at $100{ }^{\circ} \mathrm{C}$ for $4 \mathrm{~h}$.

\subsection{Pulse electrodeposition of $S n-N i / M W C N T$ composite coatings}

$\mathrm{Sn}-\mathrm{Ni} / \mathrm{MWCNTs}$ composite coatings were deposited from a chloride bath on the copper substrate. All chemicals are of analytical reagent grade, and analytic/ chemical standards were used for the preparing of the bath solutions. The multiwalled CNTs were supplied by Arry Nano with the diameter of $50-60 \mathrm{~nm}$ and length of $10 \mu \mathrm{m}$. The electrodeposition solution was comprised of $\mathrm{SnCl}_{2} \cdot 2 \mathrm{H}_{2} \mathrm{O}(28 \mathrm{~g} / \mathrm{L}), \mathrm{NiCl}_{2} \cdot 6 \mathrm{H}_{2} \mathrm{O}(15 \mathrm{~g} / \mathrm{L})$, $\mathrm{K}_{4} \mathrm{P}_{2} \mathrm{O}_{7} \cdot 3 \mathrm{H}_{2} \mathrm{O}(170 \mathrm{~g} / \mathrm{L})$, glycin $(0.5 \mathrm{~g} / \mathrm{L})$. The composite coatings were prepared with a current density of 10 , $20,40 \mathrm{~mA} / \mathrm{cm}^{2}$. The MWCNT concentration in the composite plating bath was $5 \mathrm{~g} / \mathrm{L}$. Coatings were produced under mixing of the electrolytes together with sonication during electrodeposition. A plating cell containing of the solution was immersed in a thermostatically controlled large volume water bath kept at a constant temperature of $50{ }^{\circ} \mathrm{C}$. A high-purity tin was used as the anode. The copper substrate was then activated in $25 \% \mathrm{H}_{2} \mathrm{SO}_{4}$ solution for $\approx 2 \mathrm{~min}$. This activated copper substrate was placed parallel at a distance of $5 \mathrm{~cm}$ from the vertically oriented tin plate in the plating bath. Continuous stirring of the electrolyte was performed using a magnetic stirrer and sonication was conducted using an ultrasonic processor (UP400S) $20 \mathrm{kHz}$, at a power of $60 \mathrm{~W}$, submerged at a fixed position within the plating solution in order to prevent agglomeration of MWCNTs in the electrolyte suspension. The duty cycle is defined as $t_{\mathrm{on}} /\left(t_{\mathrm{on}}+t_{\mathrm{off}}\right)$, where $t_{\text {on }}$ is the pulse-on period, and $t_{\text {off }}$ is the relaxation period.

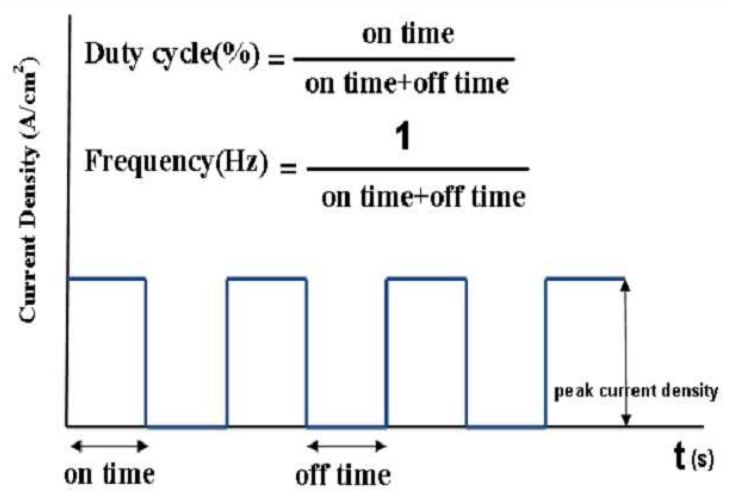

Fig. 1. Schematic diagram of the wave shape of pulse deposition.

A current waveform for the pulsed electrodeposition is illustrated in Fig. 1. The conditions of the pulse method were as follows; the bath temperature was kept at $50^{\circ} \mathrm{C}$ and the $\mathrm{pH}$ was adjusted at 8.5. Duty cycle was of $25 \%$, frequency - of $100 \mathrm{~Hz}$, deposition time - of $3.0 \mathrm{~min}$. Three different types of $\mathrm{Sn}-\mathrm{Ni} / \mathrm{MWCNT}$ nanocompos- ite films are prepared with different peak current density in the electrolyte. After co-electrodeposition, $\mathrm{Sn}-\mathrm{Ni} /$ MWCNT composite electrodes were cut into cylindrical coupons at about $16 \mathrm{~mm}$ in diameter and dried.

\subsection{Characterizations of composites}

The crystal structure and surface morphology of the composite coatings were examined with X-ray diffraction (XRD) and scanning electron microscopy (SEM), respectively. Coin type CR2016 test cells were assembled in argon filled glove box. The co-deposited Sn/MWCNT nanocomposites were used as a working electrode, $\mathrm{Li}$ foil used as counter electrode and $1 \mathrm{M} \mathrm{LiPF}_{6}$ dissolved in a mixture of ethylene carbonate (EC) and diethyl carbonate (DEC) (1:1 in volume) as the electrolyte. The working and counter electrodes were separated with polypropylene (PP) separator. Charge-discharge characteristics were obtained at $293 \mathrm{~K}$ (room temperature) between $0.02 \mathrm{~V}$ and $1.5 \mathrm{~V}$ at a constant current of $50 \mathrm{~mA} / \mathrm{g}$.

\section{Results and discussion}

Figure 2 shows the surface morphologies of the $\mathrm{Sn}-\mathrm{Ni}$ / MWCNT composite electrodes obtained at peak current densities of $20,40,60 \mathrm{~mA} / \mathrm{cm}^{2}$. These coatings were produced with constant duty cycle $(25 \%)$ and pulse frequency $(100 \mathrm{~Hz})$. The bath temperature was $50{ }^{\circ} \mathrm{C}$, and the MWCNT concentration in the composite plating bath was $5 \mathrm{~g} / \mathrm{L}$. It reveals that by increasing the peak current density from 20 to $60 \mathrm{~mA} / \mathrm{cm}^{2}$, the content of MWCNTs in the deposit increased. Surface roughness remarkably increased with increasing average current density, and a spherical morphology was observed at high peak current density (Fig. 2c). A relatively smooth

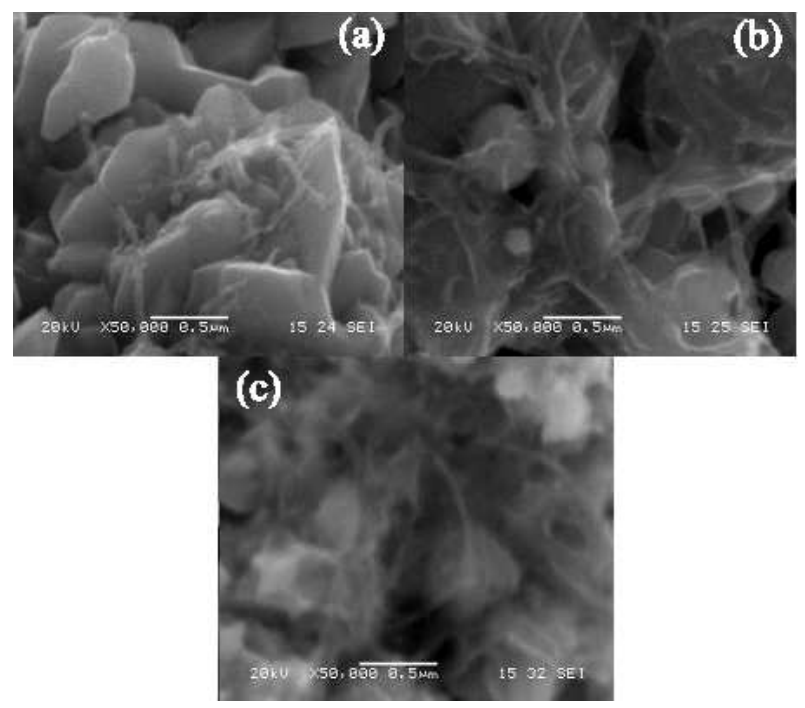

Fig. 2. SEM micrographs of $\mathrm{Sn}-\mathrm{Ni} / \mathrm{MWCNT}$ composite coatings obtained at constant frequency and duty cycle $(100 \mathrm{~Hz}$ and $25 \%)$, peak current density of (a) $20 \mathrm{~mA} / \mathrm{cm}^{2}$, (b) $40 \mathrm{~mA} / \mathrm{cm}^{2}$, and (c) $60 \mathrm{~mA} / \mathrm{cm}^{2}$. 
surface morphology was obtained at low peak current density (Fig. 2a). MWCNTs were incorporated into the $\mathrm{Sn}-\mathrm{Ni}$ matrix for whole peak current density. Spherical Sn-Ni electrodeposition incorporating MWCNTs was typically formed at peak current density of $40 \mathrm{~mA} / \mathrm{cm}^{2}$. Arai et al. [9] studied $\mathrm{Cu} / \mathrm{MWCNT}$ composite materials by electrodeposition. They found that the surface morphology of the films was affected by the current density, and a bumpy morphology surface was obtained at a high current density.

The XRD patterns of the $\mathrm{Sn}-\mathrm{Ni} / \mathrm{MWCNT}$ composite coatings produced at different peak current densities are presented in Fig. 3a. The XRD peaks were attributed to $\mathrm{Ni}_{3} \mathrm{Sn}_{4}$, and it was confirmed that $\mathrm{Ni}_{3} \mathrm{Sn}_{4}$ is the predominant phase in the deposited composite film. As expected for $\mathrm{Sn}-\mathrm{Ni} / \mathrm{MWCNT}$ composites prepared at different peak current density for pulse electrodeposition, the peaks of all samples can be ascribed to both $\mathrm{Ni}_{3} \mathrm{Sn}_{4}$ phase and $\mathrm{Ni}_{x} \mathrm{Sn}_{y}$ metastable phase according to literature data $[3,10]$. This might be due to the existence of a small amount of the $\mathrm{Ni}_{x} \mathrm{Sn}_{y}$ metastable phase, although it was not detected by XRD.

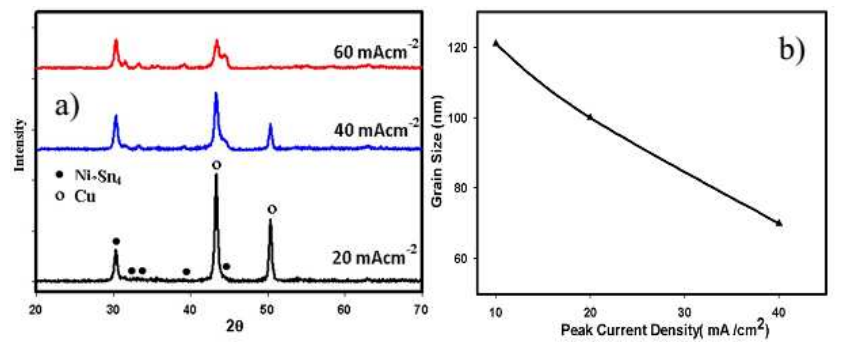

Fig. 3. Effect of peak current density (a) on phase structure, (b) on grain size of $\mathrm{Sn}-\mathrm{Ni} / \mathrm{MWCNT}$ composite coatings produced at constant duty cycle $25 \%$ and frequency $(100 \mathrm{~Hz})$.

The average grain size of the coatings was calculated from the diffraction peak width using the Scherrer equation. The MWCNT concentration in the composite coating increases with increasing the peak current density from $20 \mathrm{~mA} / \mathrm{cm}^{2}$ to $60 \mathrm{~mA} / \mathrm{cm}^{2}$. Moreover, the grain size of composite coating was found to decrease with increased peak current density in the electrodeposited composite materials (Fig. 3b). As it is well known, as the peak current density is increased the rate of formation of nuclei will be greater than the growth and the deposit will become finer-grained [11]. Moreover the presence of MWCNTs in a metal deposit may induce smaller grains due to a large increase of nucleation sites. The carbon nanotubes provide more nucleation sites and, hence, slow up the crystal growth; subsequently, the corresponding $\mathrm{Sn}-\mathrm{Ni}$ matrix in the composite coating has a smaller crystal size $[12,13]$.

Figure 4 displays the cycling stability of the $\mathrm{Sn}-\mathrm{Ni}$ / MWCNT composite electrodes produced different peak current density at a current density of $50 \mathrm{~mA} \mathrm{~g}^{-1}$ and potential between 0.02 and $1.5 \mathrm{~V}$. As shown in Fig. 4, the

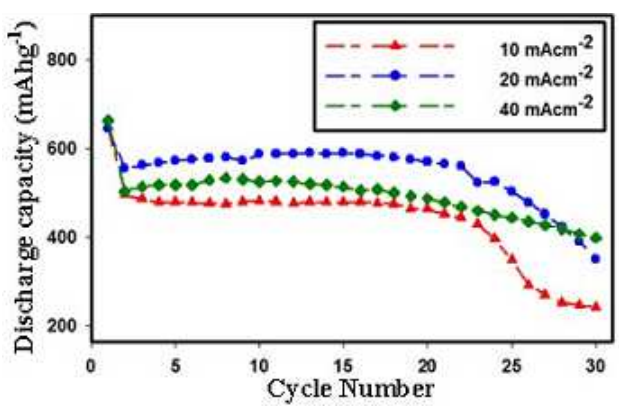

Fig. 4. Effects of peak current density on cycle performance of $\mathrm{Sn}-\mathrm{Ni} / \mathrm{MWCNT}$ composite electrode.

Sn-Ni/MWCNT (10 mA/ $\left.\mathrm{cm}^{2}\right)$, composite electrode exhibited poorer cycle performance than $\mathrm{Sn}-\mathrm{Ni} / \mathrm{MWCNT}$ $\left(40 \mathrm{~mA} / \mathrm{cm}^{2}\right)$ composite electrodes. When the peak current density increases to $40 \mathrm{~mA} \mathrm{~cm}^{-2}$, the charge capacity of the composite electrode is $512 \mathrm{mAh} \mathrm{g}^{-1}$ at the 30 th cycle, whereas that of the $\mathrm{Sn}-\mathrm{Ni} / \mathrm{MWCNT}\left(10 \mathrm{~mA} / \mathrm{cm}^{2}\right)$ composite electrode has decreased to $260 \mathrm{mAh} \mathrm{g}^{-1}$. It appears that the improvement in the $\mathrm{Li}^{+}$capacity and cycle performance of the $\mathrm{Sn}-\mathrm{Ni} / \mathrm{MWCNT}\left(40 \mathrm{~mA} / \mathrm{cm}^{2}\right)$ composite electrode is primarily due to the good dispersibility of the nanosized particles, indicates that the MWCNT, as well as the Ni nanoparticles, effectively restrains the aggregation of the $\mathrm{Sn}$ in the nanocomposite matrix, against the volume expansion of the tin anode. Based on the above results, it is concluded that $\mathrm{Sn}-\mathrm{Ni}$ / MWCNT nanocomposite can effectively buffer the volume expansion of the micro-sized Sn particles and thus stabilizes the structure of the material. In this deposited $\mathrm{Sn}-\mathrm{Ni} / \mathrm{MWCNT}$ composite electrode, there are many interfaces between the nanocrystalline particles ( $\mathrm{Sn}$ and $\mathrm{Ni}$ ) and the MWCNT. These interfaces are the most probable sites for Li storage. In addition, the high electron conductivity of the metallic nanoparticles and their plentiful interfaces with the MWCNT also ensure the high-rate performance of this $\mathrm{Sn}-\mathrm{Ni} / \mathrm{MWCNT}$ composite anode.

\section{Conclusions}

Sn-Ni/MWCNT nanocomposite coatings were deposited from a plating tin and nickel chloride bath using pulse electrodeposition. The main conclusions of the investigation are as follows. The surface morphology of the composite coating was affected by the peak current density, and a relatively smooth surface was obtained at a lower current density. The co-deposition of MWCNT in a tin electrolytic coating depends on the peak current density in bath. The MWCNT concentration in the composite coating increases with increasing the peak current density from $10 \mathrm{~mA} / \mathrm{cm}^{2}$ to $40 \mathrm{~mA} / \mathrm{cm}^{2}$. A high reversible capacity, and fairly good cyclability was achieved for $\mathrm{Sn}-\mathrm{Ni} / \mathrm{MWNT}\left(40 \mathrm{~mA} / \mathrm{cm}^{2}\right)$ electrodes. 


\section{Acknowledgments}

The authors thank the Scientific and Technological Research Council of Turkey (TÜBİTAK) for their financial support under the contract number of 111M021.

\section{References}

[1] R. Ma, Z. Lu, S. Yang, L. Xi, C. Wang, H.E. Wang, C.Y. Chung, J. Solid State Chem. 196, 536 (2012).

[2] L. Huang, H.-B. Wei, F.S. Ke, X.Y. Fan, J.T. Li, S.G. Sun, Electrochim. Acta 54, 2693 (2009).

[3] K. Nishikawa, K. Dokko, K. Kinoshita, S.-W. Woo, K. Kanamura, J. Power Sources 189, 726 (2009).

[4] L. Huang, J.-S. Cai, Y. He, F.S. Ke, S.G. Sun, Electrochem. Commun. 11, 950 (2009).

[5] N. Shin, Y.-M. Kang, M.-S. Song, D.-Y. Kim, H.-S. Kwon, J. Power Sources 186, 201 (2009).
[6] H. Guo, H. Zhao, X. Jia, Electrochem. Commun. 9, 2207 (2007)

[7] I. Amadei, S. Panero, B. Scrosati, G. Cocco, L. Schiffini, J. Power Sources 143, 227 (2005).

[8] C. Guo, Y. Zuo, X. Zhao, J. Zhao, J. Xiong, Surf. Coat. Technol. 201, 9491 (2007).

[9] S. Arai, T. Saito, M. Endo, J. Electrochem. Soc. 157, D147 (2010).

[10] Z. Da Wei, Y. Chen-ge, D. Jun, W. Jian-wu, W. Long, Trans Nonferrous Met. Soc. China 19, 1489 (2009).

[11] A. Sharma, S. Bhattacharya, R. Sen, B.S.B. Reddy, H.-J. Fecht, K. Das, S. Das, Mater. Charact. 68, 22 (2012).

[12] L. Shi, C. Sun, P. Gao, F. Zhou, W. Liu, Appl. Surf. Sci. 252, 3591 (2006).

[13] Z. Hu, X. Jie, G. Lu, J. Coat. Technol. Res. 7, 809 (2010). 